\title{
Esophagectomy for esophageal carcinoma - surgical complications and treatment
}

\author{
Radek Vrba ${ }^{a}$, Rene Aujesky' ${ }^{a}$ Monika Hrabalovaa ${ }^{a}$ Katherine Vomackovaa ${ }^{a}$ Jan Cincibuch ${ }^{b}$, Cestmir Neoral ${ }^{a}$
}

\begin{abstract}
Aim. To describe our experience with esophagectomy for esophageal cancer and, the development and treatment of complications arising from the surgery.

Material and methods. From 2007 to 8/2010, esophagectomy for esophageal carcinoma was performed in 75 patients at the $1^{\text {st }}$ Surgical Clinic. Primary esophagectomy was indicated in 20 patients with T1N0 stage or in cases where neoadjuvant treatment was contraindicated. 55 patients with T2,3N0,1 stages received neoadjuvant radiochemotherapy. Esophagectomy was performed via an abdominal approach (transhiatal laparoscopy in 44 patients, laparotomy in 3 patients) and a thoracic approach (thoracoscopy in 10 patients, thoracotomy in 18 patients).

Results. In 18 cases, one or both pleural cavities were opened by means of dissection of the mediastinal pleura during the transhiatal laparoscopic esophagectomy. The morbidity was $26.6 \%$ and the following complications were encountered: pulmonary (15 patients), anastomosis dehiscence (5), postoperative bleeding in the mediastinum (1), fistula between trachea and transposition (1), paresis of the left recurrent nerve (8), infectious complications in the abdominal cavity (2), thoracic cavity (1), and early complications (2). The sixty-day mortality was $8 \%$ and this was mostly due to pulmonary complications (4 patients) but included coronary thrombosis (1) and transposition necrosis (1).

Conclusion. The dominating complications of esophagectomy were pulmonary (20\%). The remaining serious complications cannot be completely eliminated but if diagnosed in time and treated in a correct algorithm they do not have to imminently threaten the lives of patients.
\end{abstract}

Key words: esophageal carcinoma, esophagectomy, treatment complications

Received: August 1, 2011; Accepted with revision: February 2, 2012; Available online: April 19, 2012 http://dx.doi.org/10.5507/bp.2012.019

a Department of Surgery I, University Hospital Olomouc, Czech Republic ${ }^{b}$ Department of Oncology, University Hospital Olomouc Corresponding author: Cestmir Neoral, e-mail: cestmir.neoral@fnol.cz

\section{INTRODUCTION}

The only curative approach to esophageal carcinoma is surgical operation as esophagectomy. Based on the tumour size and location, the operation is performed via a thoracic, abdominal or combined approach. In all cases it is a complex resection and reconstruction operation with high demands on the whole surgical team and great post-operative burden on the patient's organism. As for esophagectomy itself, while the associated morbidity and mortality have decreased significantly in recent years. serious complications of the surgery remain, with unfavourable outcomes on the lives of patients.

\section{MATERIAL AND METHODS}

In the last 5 years, a total of 75 patients with esophageal carcinoma have been operated on at the $1^{\text {st }}$ Surgical Clinic at the University Hospital in Olomouc. The sample comprised 64 men and 11 women, average age 55 . The duration of anamnestic difficulties varied from 14 days to 4 months, on average 61 days. The dominating symptom of the patients was dysphagia with gradual weight loss, $9 \mathrm{~kg}$ on average. Histologically, adenocar- cinoma was confirmed in 47 , squamous cell carcinoma in 28 patients.

All patients were thoroughly examined according to the established examination algorithm for esophageal carcinoma (endoscopy with tumour biopsy, endoscopic ultrasonography, PET/CT, in case of suspected tumour infiltration in the trachea or bronchi tracheobronchoscopy was selectively applied). In patients with T1N0 stage or in case neoadjuvant therapy was contraindicated (renal insufficiency, cardiomyopathy, old age), a primary esophagectomy was indicated. This was the case in 20 patients. In 55 patients with T2,3N0,1 stage, without proven disease generalization, radiochemotherapy was applied.. Radiochemotherapy consisted of a combination of concomitant radiotherapy of a total fractionized dose of $55 \mathrm{~Gy}$, and chemotherapy, a combination of 5-fluorouracil and cisplatin. In 10 patients with endoscopic stenosis of the esophageal tumour, a feeding jejunostomy was performed before the neoadjuvant treatment to improve their nutrition.

Before the esophagectomy, all patients received a cardiological, functional pulmonary and nutritional examination (nutrition screening + nutritional risk index). We chose the operation approach individually according to the location and size of the esophageal tumour. In 
Table 1. Mortality related to type of esophagectomy.

\begin{tabular}{lcccc}
\hline $\begin{array}{c}\text { Type } \\
\text { of operation }\end{array}$ & $\begin{array}{c}\text { Transhiatal } \\
\text { laparoscopy } \\
\text { esophagectomy }\end{array}$ & $\begin{array}{c}\text { Transhiatal } \\
\text { laparotomy } \\
\text { esophagectomy }\end{array}$ & $\begin{array}{c}\text { Thoracoscopy } \\
\text { esophagectomy }\end{array}$ & $\begin{array}{c}\text { Thoracotomy } \\
\text { esophagectomy }\end{array}$ \\
\hline Patients $\mathrm{n}=72$ & 44 & 3 & 10 & 18 \\
ARDS & 2 & & 1 & 1 \\
IM & 1 & & & \\
Transposition necrosis & 1 & & \\
\hline
\end{tabular}

Table 2. Complications related to type of esophagectomy.

\begin{tabular}{|c|c|c|c|c|}
\hline Type of operation & $\begin{array}{c}\text { Transhiatal } \\
\text { laparoscopy } \\
\text { esophagectomy }\end{array}$ & $\begin{array}{c}\text { Transhiatal } \\
\text { laparotomy } \\
\text { esophagectomy }\end{array}$ & $\begin{array}{l}\text { Thoracoscopy } \\
\text { esophagectomy }\end{array}$ & $\begin{array}{l}\text { Thoracotomy } \\
\text { esophagectomy }\end{array}$ \\
\hline Patients $\mathrm{n}=72$ & 44 & 3 & 10 & 18 \\
\hline Pulmonary complications & 6 & & 4 & 5 \\
\hline Anastomosis dehiscence & 3 & & 1 & 1 \\
\hline Bleeding & 1 & & & \\
\hline Fistula between trachea and transposition & 1 & & & \\
\hline Paresis recurent nerve & 4 & & 2 & 1 \\
\hline Infection complications & 2 & & & 1 \\
\hline Abscces in laparotomy & 1 & & & \\
\hline
\end{tabular}

case of tumours in distal parts of the esophagus within $30 \mathrm{~cm}$ from incisors we preferred a transhiatal laparoscopic esophagectomy for the resection stage, in total 44 patients. In three cases, due to adhesions in the area of hiatus after previous operations, esophagectomy was performed via laparoscopic approach. The reconstruction stage was always performed via mini-laparotomy and cervical incision. In most cases the passage through the upper part of the GI tract was restored by means of gastroplastic surgery maintaining blood supply via the right gastroepiploic artery. We used GIA $55 \mathrm{~mm}$ and $100 \mathrm{~mm}$ staplers to construct the gastroplastic tube. The pyloroplasty in a modification according to Holl was part of the operation. The cervical anastomosis was constructed manually with a continuous one-layer suture in all cases. In two cases we had to perform an esophagogastrectomy due to a large tumour affecting the distal oesophagus and the proximal half of the stomach, passage was restored by means of coloplasty from the traverse colon supplied by the middle colic artery. In tumours located in the proximal and middle esophagus, we opted for an esophagectomy via thoracic access. In 10 patients we extirpated the esophagus using a mini-invasive right-sided thoracoscopy. In 18 patients with a large tumour of the middle and proximal esophagus where there was suspicion of infiltration to the tracheobronchial tree, we indicated a right-sided posterolateral thoracotomy. The reconstruction stage was performed in the same way as in laparoscopic or laparotomic esophagectomy. We standardly left two drains in the abdominal cavity (area of the left hypochondrium and under the left liver lobe). One drain was introduced into the cervical anastomosis, and during the esophagectomy two drains were applied in the right pleural cavity. In all patients, after finishing the reconstruction phase in the GI tract, a biluminal jejunal nutrition tube was introduced to assure intestinal nutrition and decompression of the transposition. The patients' nutrition in the post-operative stage was ensured by means of a combination of parenteral and intestinal nutrition. Usually on the seventh day after the operation, examination of the upper part of the GI tract was performed using an aqueous contrast agent to check the sufficiency of the anastomosis. In case of a positive finding the patients were gradually realimented.

Based on TNM classification, definite histopathological examination of the resected esophagus with tumour determined the following disease stages in our patient set: stage I. 6 patients, stage II.A 16 patients, stage II.B 11 patients, stage III. 16 patients, stage IV. 14 patients. In 12 patients we recorded a complete response to the oncologic treatment without histopathological detection of tumour in the resected specimen.

\section{RESULTS}

During the operation, we recorded an opening of one or both pleural cavities in $18(41 \%)$ patients in the transhiatal laparoscopic esophagectomy. The opened pleural cavities were treated by introducing unilateral or bilateral thoracic drainage. In most cases of pleural cavity opening, the tumour was large and infiltrated the mediastinal pleura. We consider the opening of the mediastinal pleuras to be a complication only in patients with complete tumour response after oncological treatment. This was the 


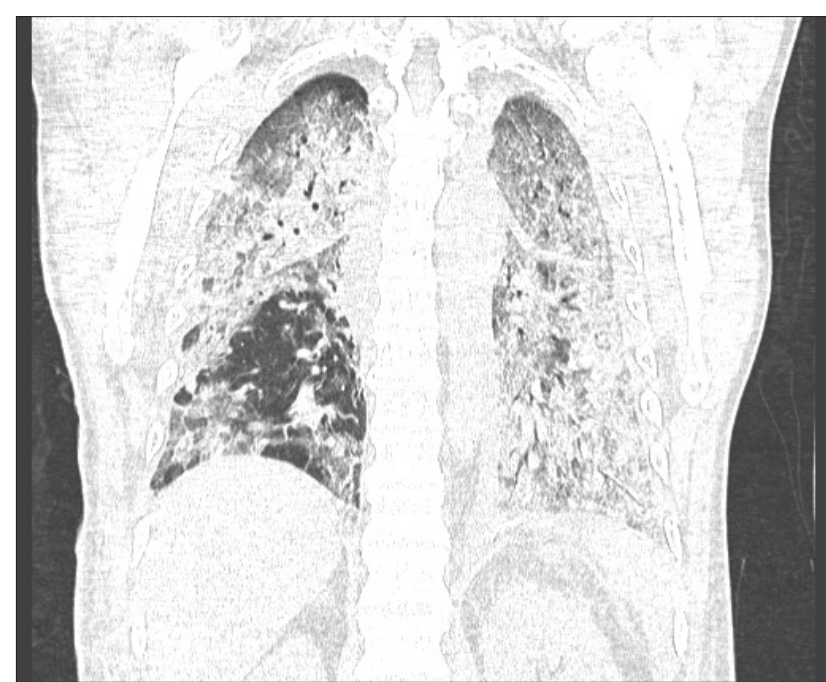

Fig. 1. CT of lungs with ARDS.

case in $4(9 \%)$ patients. Post-operative bleeding appeared in 1 patient $(1.3 \%), 4 \mathrm{~h}$ after transhiatal laparoscopic esophagectomy there was mediastinal bleeding from the right-sided thoracotomy.

The most frequent post-operative complications in the patient set were pulmonary complications, seen in 15 patients $(20 \%)$, in 6 cases of transhiatal laparoscopic esophagectomy, in 4 cases of thoracoscopic and in 5 cases of thoracotomic esophagectomy. In 10 cases we managed to treat the pulmonary complications successfully. Therapy was modified according to the clinical condition of the patient, mostly in combination with artificial pulmonary ventilation, in some cases necessitating tracheostomy, antibiotic therapy, corticotherapy and bronchoscopic toilet of the airways. In five patients $(6.6 \%)$ a dehiscence of the cervical anastomosis was observed. In four of these cases, due to the good clinical condition of the patient and minimal dehiscence, we successfully treated the dehiscence conservatively. In one case the dehiscence was treated surgically, by means of drainage and toilet. In one patient (1.3\%) a cough appeared on the $11^{\text {th }}$ day together with fever and respiratory difficulties. The upper GI series performed on the $7^{\text {th }}$ post-operative day produced favourable findings on the cervical anastomosis, without fistula between the transposition and airway. Tracheobronchoscopy and follow-up upper GI series showed a fistula between the gastroplasty and trachea. We treated the fistula by introducing a biodegradable stent in the gastroplasty. Follow-up upper GI series were without fistula with a correctly positioned stent in the gastroplasty. The patient was realimented and subsequently discharged from hospital in a good clinical condition. Paresis of the left recurrent nerve was seen in 8 patients $(10.6 \%)$. As for infectious complications, a subphrenic abscess after splenectomy was observed in two cases (2.6\%), and a right-sided thoracic empyema was observed in one patient $(1.3 \%)$. The subphrenic abscesses were treated by targeted pigtail drainage under $\mathrm{CT}$. The thoracic empyema was treated by thoracic drainage. We recorded early complications in two patients $(2.6 \%)$. In both cases an abscess

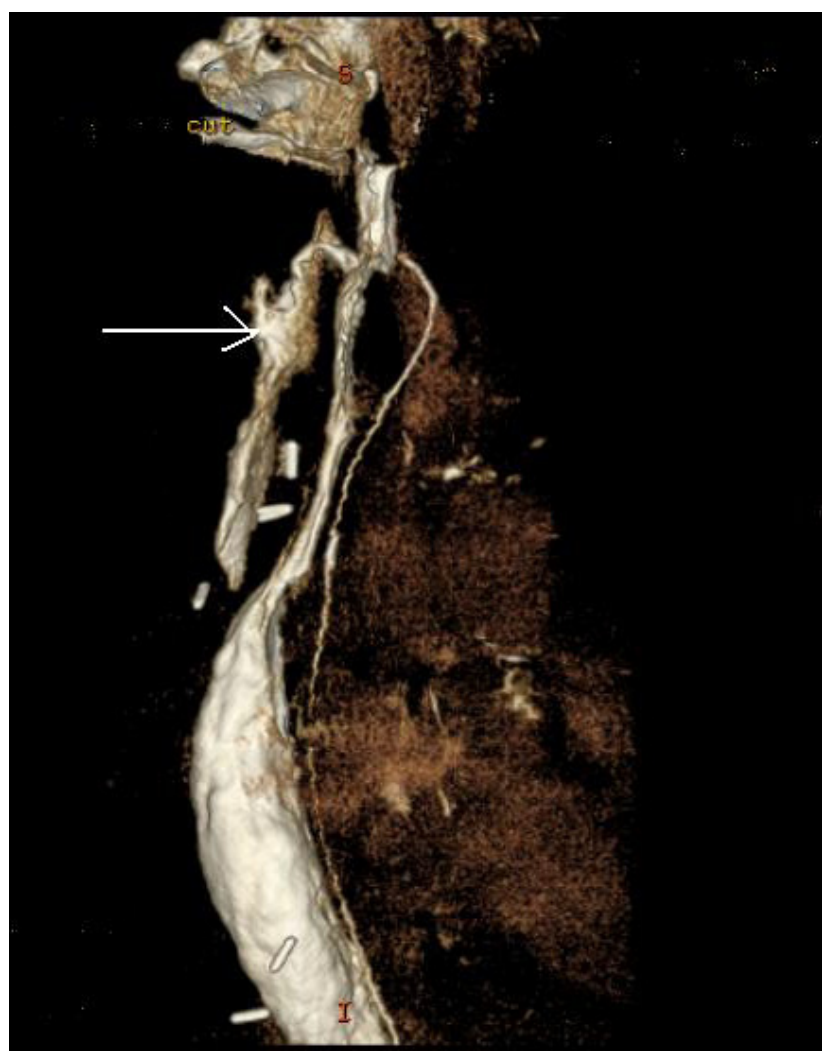

Fig. 2. CT of fistula in neck anastomosis.

was discovered in the laparotomy. The total morbidity of the operated patients was $26.6 \%$. In some patients several complications were observed.

The sixty-day mortality of our sample of patients was $8 \%$; in four cases of patients with respiratory complications, lethal ARDS developed. A large acute coronary thrombosis on the $4^{\text {th }}$ post-operative day was the cause of death in one patient. In one case there was gradual development of septic shock with suspicion of gastroplasty necrosis, which was confirmed during surgical revision. A gastroplasty resection, a cervical esophagostomy and feeding jejunostomy were performed. However, the patient died of the after-effects of severe shock.

\section{DISCUSSION}

Esophagectomy is a demanding surgical operation which, in combination with the generally unfavourable state of the patients (older patients, with poor nutrition and severe comorbidities), presents an extreme burden on the organism of the operated patients ${ }^{1}$. As is the case in other demanding operations, it is not possible to entirely eliminate the development of complications after esophagectomy which may have fatal consequences for patients if not diagnosed and adequately treated in time. Generally, most post-operative complications present in the first five post-operative days ${ }^{2}$. Lately there has been a significant improvement in immediate post-esophagectomy results in comparison with the past. The mortality is within $1.0 \%$ to 


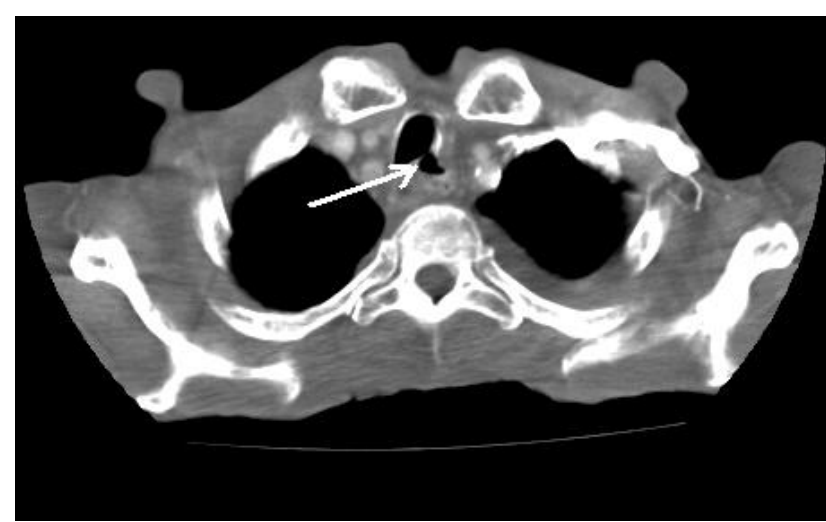

Fig. 3. CT of fistula between trachea and gastroplasty.

$5.8 \%$ based on current literary references and the morbidity varies from $17.9 \%$ to $58 \%$ (ref. $^{3-5}$ ).

Pulmonary complications are the most common cause of death after an esophagectomy, with am incidence from $19.3 \%$ (Mariette) to $44.4 \%$ (Ott) $\left(\right.$ ref. $^{3-7}$ ). Older patients are most often threatened by these complications, as well as those with chronic nicotine abuse, malnutrition, pulmonary dysfunction and immunity disorders ${ }^{5,7}$. Ott describes a $3.8 \%$ mortality in a sample of 240 patients after IvorLewis ' esophagectomy for distal esophageal adenocarcinoma. Nevertheless pulmonary complications were causes of death in $50 \%$ of the patients ${ }^{3}$. The total mortality of a sample of 379 patients after esophagectomy published by Atkinson was 5.8\%. The dominating cause of death was pneumonia in $54 \%$, subsequent secondary respiratory failure due to pneumonia was the cause of death in $81 \%$ (ref. $^{8}$ ). In a sample of 432 patients in stages I-IV according to the UICC classification who had undergone transthoracic or transhiatal resection of the esophagus, Siewert reports pulmonary complications (pneumonia or ARDS) in 22.9\%. Baba refers to pulmonary complications in $23.6 \%$ of patients after a three-cavity dissection of the esophagus $^{8,9}$. In the literature, no significant difference in pulmonary complications has been described between the transthoracic and tranhiatal approach for esophageal resection $^{8,10}$. Also, in patients who primarily received neoadjuvant oncological treatment, no greater pulmonary complications were found after esophagectomy ${ }^{3,10}$. The incidence of pulmonary complications may be influenced in the pre-operative stage by improving pulmonary function, and during the operation by appropriate anaes-

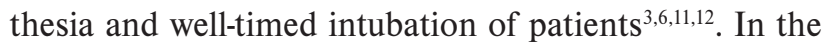
post-operative stage, intensive pulmonary rehabilitation with mobilization of all patients after esophagectomy is necessary, and based on the clinical state of the patient, a bronchoscopic toilet of the airways may be indicated. The published literature confirms our experience of respiratory complications as the most common cause of death following esophagectomy.

Cardiac complications, generally stated as approximately $10 \%$, may significantly influence the immediate lethality after the operation ${ }^{5,13}$. In our sample, we recorded 1 death due to a large coronary thrombosis on the $4^{\text {th }}$ day after the operation.
One serious complication which may have fatal consequences is necrosis of the transposition. Whooley described necrosis of the transposition in $0.8 \%$ of patients in a sample of 710 patients operated on for esophageal carcinoma $^{13}$. The most common cause of necrosis of the transposition is ischemia which is a more frequent in coloplasty than gastroplasty. This was confirmed by Moorehead and Wong in a sample of 760 esophagectomies: gastroplasty ischemia was described in $0.5 \%$, in cases of jejunal interposition in $11.3 \%$ and in patients with coloplasty in $13.3 \%$ (ref. $^{14,15}$ ). Necrosis of the transposition is characterized by a total alteration of the state of the patients (unexpected tachycardia, respiratory failure, increase in inflammatory factors, lactate increase). The diagnosis is made endoscopically and by means of surgical revision. If confirmed, extirpation of the transposition is indicated with a cervical esophagectomy and feeding jejunostomy. In the second phase, reconstruction of the GI tract by means of coloplasty is performed ${ }^{14}$. We recorded this complication in 1 patient. Unfortunately, as stated the patient died of consequent septic shock.

Anastomosis dehiscence in the referred samples of operated patients ranges between $2 \%$ and $14 \%$ (ref. ${ }^{3,6,8}$ ). Anastomosis dehiscence is more often described when using the cervical approach than in an anastomosis performed in the thorax. In coéntrast, dehiscence in the thorax shows a lethality of up to $60 \%$ with development of mediastinitis and organ failure after septic shock ${ }^{16}$. Construction of the cervical anastomosis is performed manually at most hospitals. On the other hand, in the thorax a stapler anastomosis is preferred as it has a slightly lower percentage of dehiscence ${ }^{16,17}$. Patients threatened by dehiscence formation are patients with comorbidities, after neoadjuvant treatment and with ischemia of the anastomosis. In most cases it presents within 10 days of the operation ${ }^{15,16}$. The treatment of cervical dehiscence depends on the clinical condition of the patient and degree of dehiscence. In cases of a clinically good condition and minimal dehiscence, a conservative approach is possible, otherwise drainage of the dehiscence and antibiotic treatment are needed. The outlook on treatment of anastomosis dehiscence in the thorax is controversial in the literature; therapy is modified individually according to the size of the fistula and overall patient condition. Especially in cases of small dehiscence, in some publications, endoscopic therapy is preferred using tissue glue, endoclips and stents ${ }^{18,16}$. Schubert et al. report the successful treatment of 25/27 patients with dehiscence in anastomosis. In the case of slight dehiscence up to $30 \%$, this was treated with fibrin glue or clips. In cases of larger dehiscence a stent was introduced ${ }^{20}$. In cases of larger dehiscence, drainage of the area of the fistula is indicated mini-invasively under CT control or by means of the classical surgical approach from thoracotomy ${ }^{21}$. In both situations patients are in a serious condition and the therapy has to be modified according to the actual clinical state. Administration of broad-spectrum antibiotics and full parenteral therapy are necessary. If prolonged conservative treatment is required, a feeding jejunostomy is needed to ensure patients ' nutrition. In our department 
we definitely prefer performing the anastomosis manually via the cervical approach. We recorded dehiscence in 5 cases in our sample and treated them according to the clinical condition of the patients and the grade of dehiscence based on findings on the upper GI series.

A less frequent but more serious complication of esophagectomy that may result in a potentially lethal complication is a fistula between the neoesophagus and the airways, in most cases the trachea. The incidence according to the literature is between $0.3-0.5 \%$ (ref. ${ }^{22}$ ). Clinically it is characterised by an alteration of the patient's overall condition with repeated aspirations and pneumonia ${ }^{23}$. The diagnosis is based on findings on the upper GI series, endoscopically and bronchoscopically ${ }^{22,24}$. After managing the acute symptoms of the complication, the fistula may be treated endoscopically by introducing coated stents into the transposition or into the airways ${ }^{25}$. We have to admit that in most cases the treatment fails and it is necessary to surgically treat the fistula, by resection of the fistula and suture of the transposition and the trachea and, implantation of a muscle flap between the GI tract and the airways ${ }^{26,27}$. In our sample, this complication occurred in one patient. The fistula was treated by implanting a biodegradable coated stent into the transposition; however, there was a distal dislocation and the patient had to subsequently be treated surgically.

Among less frequent complications in the post-operative stage is a chylothorax ${ }^{13}$. If confirmed, this is treated conservatively, if unsuccessful, it is necessary to perform ligation of the thoracic duct.

Paresis of the left recurrent nerve after an operation appears quite frequently ${ }^{6}$. The literature on paresis of recurrent nerve varies between 4\% (Nagel) and 67\% (Nishimaki) (ref. ${ }^{28}$ ).

During a transhiatal esophagectomy, preparation of the distal oesophagus into the mediastinum is threatened with opening of the pleural cavity with subsequent formation of pneumothorax ${ }^{7,10}$. In most cases, this complication is noted during the operation. Treatment consists of introducing thoracic drainage. If pneumothorax develops in the post-operative stage, Bülau thoracic drainage is applied.

All patients are threatened with the typical complications of surgery (bleeding, injuries of structures in the operating field, adhesive ileus, early complications). If these complications are diagnosed and treated in time, they usually have no influence patient mortality ${ }^{29}$.

\section{CONCLUSION}

Respiratory complications significantly influence the mortality of patients after esophagectomy. Treatment is difficult and not always successful. Other serious complications such as necrosis of the transposition, fistula between the neoesophagus and airways and dehiscence of the thoracic anastomosis, do not appear in a high percentage but may also negatively influence post-operative mortality. Early diagnosis and treatment of all complica- tions according to the established algorithm is essential. To improve the surgical outcome of esophagectomy, of paramount importance are, precise pre-operative patient staging and performing the esophagectomy in specialized centres which have comprehensive experience in esophageal carcinoma treatment ${ }^{30,31}$.

\section{REFERENCES}

1. Lund O, Kimose HH, Aagaard MT, Hasenkam JM, Erlandsen M. Risk stratification and long-term results after surgical treatment of carcinoma of the thoracic esophagus and cardia. A 25-year retrospective study. J Thorac Cardiovasc Surg 1990;99:200-9.

2. Wahl W, Probst C, Schlick T, Dutkowski P, Junginger T. Pulmonale Komplikationen nach Oesophagusresektion. Zentralbl Chir 1999;124:483-8.

3. Ott K, Bader FG, Lordick F, Feith M, Bartels H, Siewert JR. Surgical factors influence the outcome after Ivor-Lewis esophagectomy with intrathoracic anastomosis for adenocarcinoma of the esophagogastric junction: a consecutive series of 240 patient at an experienced center. Ann Surg Oncol 2009;16:1017-25.

4. Atkins BZ, Shan AS, Kelley A, Hutcheson KA, Mangum JH, Pappas TN, Harpole DH, Dámico TA. Reducing hospital morbidity and mortality following esophagectomy. Ann Thorac Surg 2004;78:1170-6.

5. Ferguson MK, Durkin AE. Preoperative prediction of the risk of pulmonary complications after esophagectomy for cancer. J Thorax Cardiovasc Surg 2002;123:661-9.

6. Dumont P, Wihlm JM, Hentz JG, Roeslin N, Lion, R, Morand G. Respiratory comlications after surgical treatment of esophageal cancer A study of 309 patients according to the type of resection. Eur J Cardioithorax Surg 1995;9:539-43.

7. Griffin SM, Shaw IH, Dresner SM. Early complications after Ivor- Lewis subtotal esophagectomy with two-field lymfadenectomy: risk factor and management. J Am Coll Surg 2002;194:285-97.

8. Becker HD, Hohenberger W, Junginger T, Schlag PM. Chirurgická onkologie: Grada; 2005.

9. Baba M, Aikou T, Yoshinaka H, Natsugoe S, Fukumoto T, Shimazu H, Akazawa K. Low-term results of subtotal esophagectomy with threefield lymfadenectomy for carcinoma of the thoracic esophagus. Ann Surg 1994;219:108-13.

10. Dahn D, Martell J, Vorwerk H, Hess CF, Becker H, Jung K, Hilgers R, Wolff HA, Hermann RM, Christiansen $\mathrm{H}$. Innfluence of irradiated lung volumes on perioperative morbidity and mortality in patients after neoadjuvant rediochemotherapy for esophageal cancer. In J Radiat Oncol Biol Phys 2010;1:44-52.

11. Bartels H, Stein HJ, Siewert JR. Preoperative risk analysis and postoperative mortality of esophagectomy for resectable esophageal cancer. Br J Surg 1998;85:840-4.

12. Bartels $\mathrm{H}$, Stein $\mathrm{HJ}$, Siewert JR. Risk analysis in esophageal surgery. Resent Result Cancer Res 2000;155: 89-96.

13. Whooly BP, Law S, Murthy SC, Alexandrou A, Wong J. Analysis of reduced death and complication rates after esophageal resection. Ann Surg 2001;233:338-44.

14. Wormuth JK, Heitmiler RF. Esophageal conduit necrosis. thorac Surg Clin 2006;16:11-22.

15. Briel JW, Tamhankar AP, Hagen JA, DeMeester SR, Johansson J, Choustoulakis E, Peters JH, Bremner CG, DeMeester TR. Prevalence and risk factors for ischemia, leak, and strictures of esophageal anastomosis: gastric pull-up versus colon interposition. J Am Coll Surg 2004;198(4):536-41.

16. Ursehel JD. Esophagogastrostomy anastomotic leaks comlicating esophagectomy: a review. Am J Surg 1995;169(6):634-40.

17. Turkuilmaz A, Eroglu A, Aydin Y, Tekinbas C, Erol Muharrem M, Karaoglanoglu N. The managment of esophagogastric anastomotic leak after esophagestomy for esophageal carcinoma, Dis Esophagus 2009;22:119-26.

18. Fernandez FF, Richter A, Freundeberg S, Wendl K, Manegold BC. Treatment of endoscopic esophageal perforation. Surg Endosc 1999;13:962-6.

19. Pross M, Manger T, Reinheckel T, Mirow L, Kunz H, Lippert H. Endoscopic treatment of clinically symptomatic leaks of thoracic esophageal anastomoses. Gastrointest Endosc 2000;51(1):73-6. 
20. Schubert D, Pross M, Nestler G, Ptok H, Scheidbach H, Fahlke J, Lippert $\mathrm{H}$. Endoscopic treatment of mediastinal anastomotic leaks. Zentralbl Chir 2006;131:369-75.

21. Crestanello JA, Deschmaps C, Cassivi SD, Nichols FC, Allen MS Schleck C, Pairolero PC. Selective managment of intrathoracic anastomatic leak after esophagestomy. Adv Surg 2006;40:173-90.

22. Buskens CJ, Hulscher JBF, Fockens P, Obertrop H, Van Lanschot JJB. Benign tracheo-neo-esophageal fistulas after subtotal esophagectomy. Ann Thorac Surg 2001; 72: 221-224.

23. Nardella JE, Van Raemdonck D, Piessevaux $H$, Deprez $P$, Doissard $R$ Staudt JP, Heuker D, van Vyve E, Gastro-tracheal fistula - unusual and life threatening complication after esophagestomy for cancer: a case report. J Cardiothorac Surg 2009;29:69.

24. Pramesg CS, Sharma S, Saklani AP, Sanghvi BV. Broncho-gastric fistula complicating transthoracic esophagectomy. Dis Esophagus 2001;14:271-3.

25. Freire JP, Feijo SM, Miranda L, Santos F, Castelo HB. Tracheoesophageal fistula: combined surgical and endoscopic approach. Dis Esophagus 2006;19:36-9.
26. Hayashki K, Ando N, Ozawa S, Tsujika K, Kitajima M, Kaneko T. Gastric tube-to-tracheal fistula closed with a latissismus Dorsi myocutaneous flap. Ann Thorac Surg 1999;68:561-2.

27. Suk-Wok S, Hyung-Sung L, Moon Soo K, Jong Mog L, Jae Hyun K, Jae Z III: Repair of gastrotracheal fistula with a pedicled perigastrial flap after Ivor-Lewis esophagogastrectomy for esophageal cancer. J Thorac Cardiovasc Surg 2006;132:716-7.

28. Nishimaki T, Suzuki T, Kanda T, Obinata I, Komukai S, Hatakeyma K. Extended radical esophagectomy for superficially invasive carcinoma of the esophagus. Surgery 1998;125:142-7.

29. Vrba R, Neoral Č, Aujeský R. Karcinom žaludku - výskyt a řešení komplikací chirurgické léčby. Rozhledy v chirurgii 2010;3:178-83.

30. Mariette C, Taillier G, Van Seuningen I, Triboulet JP. Factor affecting postoperative course and survival after en bloc resection for esophageal carcinoma. Ann Thorac Surg 2004;78:1177-83.

31. Qureshi AU, Iqbal M, Gonda KM. Transhiatal esophageal surgery for malignancy a 7-year experience at tertiary care hospitál. J Coll Physicians Surg Pak 2009;19:413-6. 